\title{
CÀNONS DEL CONCILI DE LLEIDA DE 1173 AL.LUSIUS A LA PAU I TREVA*
}

\author{
Gener Gonzalvo i Bou
}

Les actes originals del concili lleidatà de 1173 no han arribat fins a nosaltres. En coneixem el text mitjançant la publicació d'una còpia de 1788, també fruit de diversos trasllats procedents originàriament d'un còdex que posseïa el bisbe d'Astorga Manuel Abad i Lassierra ${ }^{1}$. Cap de les grans col-leccions conciliars no han recollit les resolucions de 1173 establertes a Lleida (Labbé, Mansi, etc.). La presència de l'arquebisbe de Tarragona ens indica el seu caràcter de concili provincial, però ni els reculls de textos conciliars tarragonins que he consultat ni els arxiepiscopologis, fonts molt escadus-

- Prenc com a referència la meva tesi de llicenciatura, Les assemblees de Pau i Treva a Catalunya. Origens i descabdellament fins a Jaume I, Ilegida l'any 1984 a la Universitat Autònoma de Barcelona, i dirigida pel Dr. Frederic Udina i Martorell. En l'ampliació d'un aspecte puntual d'aquest treball vull mostrar el meu agraïment al Dr. Udina pel seu ajut inestimable.

1 P. SAINZ DE BARANDA, «De la Santa Iglesia de Lérida en su estado moderno», España Sagrada XLVII, Madrid 1850, pp. 152-161. Traduccí́ castellana. Del mateix autor, «La Santa Iglesia de Barbastro en sus estados antiguo y moderno", España Sagrada XLVIII, Madrid 1862, pp. 301-307. Text llatí: J. TEIADA Y RAMiRo, Colección de Cánones y de todos los Concilios de la Iglesia española HI, Madrid 1859, pp. 278-286. Publica el text llatí extret de Sainz de Baranda. 
seres en dades anteriors al segle XII, esmenten per a res l'assemblea eclesiàstica de Lleida ${ }^{2}$. Pons i Gurí indica que Jaume Villanueva pensava publicar els textos conciliars tarragonins, sobretot emprant un còdex del convent dels Carmelites Descalços de Lleida, avui desaparegut. En aquell moment, molts manuscrits eren perduts, i després del 1835 foren destruitts nombrosos fons monàstics ${ }^{3}$. Villanueva no esmenta aquest concili. Per tant, hem de refiar-nos de les successives còpies que enumera Sainz de Baranda ${ }^{4}$, el qual confessa que alguns d'aquests copistes retocaren el nombre de cànons i el text. Malgrat tot, i a desgrat de l'«advertiment» que anota l'Acadèmia de la Història en la publicació del text llatí ${ }^{5}$, totes les dades ens indiquen la versemblança de la celebració del concili ( 6 de febrer de 1173). Aquest fou presidit pel cardenal diaca de Santa Maria in Cosmedin, Jacint Bobo, legat pontifici 6 , més tard elegit papa, que va prendre el nom de Celestí III (1191-1198) ${ }^{7}$. L'arquebisbe de Tar-

2 Constituciones Sacrorum Conciliorum Tarraconensium sub illustri et reverendissimo in Christo patre D.D. Hieronymo de Aurea..., Barcelona 1577, ed, de Claudi Bornat; A. Augustini, Opera Omnia III, Luca, ed. de 1767.

3 J.M. PONS I GuRf, «Constituciones Conciliars Tarraconenses (1229 a 1330)», Analecta Sacra Tarraconensia 47, 1974, pp. 65-128.

4 P. SAINZ DE BARANDA, op. cit., pp. 150-152.

5 España Sagrada XLVIII, pp. 297-298.

${ }^{6}$ Les primeres notícies de l'acció de Jacint a la península com a legat papal sembla que són la seva assistència als concilis de Salamanca (1154) i Valladolid (1155). Sobre aquest punt, cal veure els treballs de F. FitA al Boletín de la Real Academia de la Historia XIV, 1889, pp. 530-555, i XXIV (1984), pp. 467-475. Són conegudes les cites de la presència del legat anotades per ZURrTA als Anales de la Corona de Aragón I, lib. II, Saragossa 1669, cap. XXIX, f. 77v (conquesta d'Albarrasi) i cap. XxxIII, f. 80v (noces d'Alfons I, a. 1174). Altres referències de Jacint: E. MORERA, Tarragona Cristiana 1, Tarragona 1897, pp. 483-484, 492 i 574-575. Cita el concili de 1173 i la conquesta de Conca, impulsada pel legat; C. Hefelde et H. LeClerco. Histoire des Conciles V. 2a part, Paris 1913, p. 911 (concili de Valladolid, 1155); P. KeHR, Papsturkunden in Spanien I, Berlin 1926. Publica nombrosa documentació referida a Jacint: docs. 66, 103, 106, 109, 110, 118 i 155, pp. 339-452 (anteriors al concili de 1173) i docs. 157, 159, 160 i 161 . pp. $453-459$ (posteriors). Destaca el doc. 155 , en què Jacint concedeix privilegis a l'Església de Lleida (a. 1173). Cita el concili lleidatà de 1155 (p. 221).

7 Sobre Celesti III: J. B. W ATTERICH, Romanorum Pontificum Vitae, Leipzig 1862; P. JAFFE, Regesta Pontificum Romanorum II, Leipzig 1888, pp. 577-644, 727 i 771-772; J. LeINEWEBER, Studien zur Geschichte Papst Calestius III, Jena 1905. 
ragona era Guillem de Torroja (1171-1174), assistent en qualitat de metropolità. En el text actual no hi figuren els noms dels bisbes de la província, segurs participants (hi manquen també les signatures $)^{8}$. És, per tant, una assemblea estrictament eclesiàstica, sense la participació de l'autoritat laica, i de marcat signe disciplinari.

El text inclou vint-i-sis cànons. D'aquests, set tenen relació amb els estatuts de Pau i Treva, encara que explícitament no hi apareix la clàssica expressió pace et treuga (cànons XIV, XV i XXI-XXV). Els preceptes restants inclouen normes habituals en concilis i sínodes normatius de l'època: celibat, incest, impediments per rebre els ordes, béns eclesiàstics, etc., que afecten bàsicament l'estament clerical, encara que no de manera exclusiva. Intentarem breument detallar el contingut d'aquest cànons al-lusius a la Pau i Treva. El cànon XIV impedeix la sepultura als cristians morts en accions violentes temeràries. El XV és un clàssic dins les normes de la Pau de Déu: es protegeixen els preveres, clergues, monjos, pelegrins, mercaders, camperols, animals i béns del camp, amb la pena d'excomunió per als violadors. En els sínodes catalans del segle XI es recullen aquests preceptes, sota la iniciativa de l'abat-bisbe Oliba, assumint la tradició de la Pau de Déu francesa, que ja s'havia començat a formular el darrer decenni del segle X. Concretament, ens estem referint al sínode de Toluges de 1027, primer text de Pau i Treva que ha arribat fins als nostres dies, i també mereixen especial atenció els dos sínodes de Vic de 1030 i 1033, el concili de Toluges de 10641066, un nou sínode de Vic valid també per a la diòcesi de Girona, també celebrat durant el període aproximat de 1064-1066, i, finalment, el concili de Girona de 1068 , que comptà amb la presència d'un legat pontifici, el cardenal Hug Càndid. Les assemblees que

8 Sobre Guillem de Torroja: J. SÁnCHEZ REAL, El Archiepiscopologio de Luis Pons de Icart, Tarragona 1954, pp. 78-85. Edició del manuscrit de 1572. El breu arxiepiscopologi que prologa les Constitucions Conciliars editades el 1577 (veg. nota 3); J. BLANCH, Arxiepiscopologi de ia Santa Església Metropolitana i Prima. da de Tarragona. Edició de 1951 del manuscrit de 1665, pp. 105-111 i 154; J. VILLANUEYA, Viaje Literario a las Iglesias de España XIX, Madrid 1851, pp. 160163; S. Puig I PuIG, Episcopologio de la Sede Barcinonense, Barcelona 1929, pp. 157-169 (per al període de bisbe de Barcelona. Dóna notícies del cardenal Jacint, pp. 158 i 165). 
foren reconduïdes pel poder laic assumiren aquests estatuts de defensa establerts per les assemblees eclesiàstiques abans comentades. En aquest cas, són molt importants les que tingueren lloc a Barcelona el 1064, la Pau i Treva d'Olèrdola de 1108, i l'assemblea vàlida bàsicament per al comtat de Cerdanya de $1118^{\circ}$. Seguint amb el comentari dels cànons del concili lleidatà de 1173, el XXI disposa que l'excomunicat que hagi violentat algun clergue o qualsevol persona eclesiàstica, o que els hagi fets presoners, no sigui absolt per cap bisbe (exceptuant-ne el cas de perill de mort). El violador solament podrà ésser perdonat pel pontífex romà, al qual haurà de presentar-se i donar la satisfacció corresponent. Aquesta obligació l'haurà de complir quan, absolt pel bisbe en cas de mort, hagi recobrat la salut ${ }^{10}$. El cànon XXII excomunica els violadors de les esglésies o els seus cementiris ${ }^{11}$. El XXIII mana que el que hagi estat excomunicat pel seu bisbe o arquebisbe a causa d'algun delicte manifest, causant perjudicis, violant, robant o molestant, sigui al prelat o bé als seus homes o béns, resti en l'excomunicació fins que no hagi restituït el dany comès o doni seguretats de fer-ho. En cas de perill de mort, podrà rebre el sagrament de la penitència i el vià-

9 A la meva tesi de llicenciatura indico les referències arxivístiques i bibliografiques relatives a les assemblees comentades, algunes anotades en aquest treball. Sobre aquest període inicial: J.M. FonT Rius, aLos inicios de la Paz y Tregua en Cataluñan, Estudios juridicos en honor del profesor Octavio Pérez Vitoria I, 1983, pp. 235-250 (excel-lent síntesi sobre la problemàtica de les assemblees de 1027. 1030 i 1033). Aquest cànon XV fou establert en el concili Laterà I (1123), cànon XX (D. MANSI, Sacrorum Conciliorum Nova et Amplissima Collectio, 31 vols., Firenze-Venezia 1759-1798, XXI, col. 286) i ratificat en els de Clermont (1130), canon VIII (MANSI XXI, col. 439), Reims (1131), cànon X (MANSI XXI, col. 460), Laterà II (1139), cànon XI (MANSI XXI, col. 529), Reims (1148), cànon XI (MAN SI XXI, col. 716), Reims (1157), cànon III (MANSI XXI, col. 844) i Tours (1163), cànon XI (MANSI XXI, cols. 1183-1184).

10 Acordat en el concili de Clermont (1130), cànon X (MANSI XXI, col. 439), Reims (1131), cànon XIII (MANSI XXI, col. 461), Pisa (1135), cànon XII (MansI XXI, col. 490), Laterà II (1139), cànon XV (MANSI XXI, col. 530) i Reims (1148), cànon XIII (MANSI XXI, col. 717).

11 Establert en els concilis de Reims (1131), cànon XIV (MANSI XXI, col. 461), Pisa (1135), cànon XIV (MANSI XXI, col, 490), Laterà II (1139), cànon XV (MANSI XXI, col, 530) i Reims (1148), cànon XIV (MANSI XXI, col. 717). 
tic, però no gaudirà de sepultura eclesiàstica. El cànon XXXIV comdemna els anatemitzats a la incomunicació, privant-los de qualsevol contacte amb la resta de fidels, que són amenaçats amb igual condemna en cas de violar aquest precepte ${ }^{12}$. Finalment, el XXV esdevé un atac terrible als incendiaris, crim considerat com la més devastadora de les pestes, ruïnosa per al poble de Déu, no solament perjudicial per als cossos o per a les ànimes, ans també condemna vinguda de l'autoritat de Déu i dels apòstols Pere i Pau. El qui hagi violat aquest precepte, resta excomunicat fins que no hagi restituit el mal material, jurant no tornar a cometre el crim, i complint la penitència de servir en els exèrcits de Jerusalem o d'Espanya durant un any sencer. S'estableix igualment que si un bisbe no porta a terme aquest manament, haurà de restituïr, i li serà interdit d'exercir durant un any els oficis pontificals. Finalment, es concedeixen facultats a reis i prínceps per a l'administració de la justícia, aconsellats pels arquebisbes $i$ bisbes 13 .

El precedent més inmediat d'aquest text dins el territori català el constitueix el concili de Lleida de 1155, conduït també pel legat pontifici Jacint. Ferran Valls i Taberner en féu un estudi, basat en un manuscrit dipositat a la Biblioteca de Catalunya. Valls detectà els grans paral-lelismes existents entre ambdues assemblees ${ }^{14}$. Manca, però, en el concili de 1173 qualsevol referència explícita a la Treva de Déu, renovada en el concili de 1155 i prenent com a base els concilis ecumènics laterans ${ }^{15}$. No descartem, però, que la Treva

12 Aquest precepte sovinteja en els estatuts catalans de Pau i Treva del segle XI, com és el cas del sínode de Toluges de 1027 (actes publicades per E. BALuZE dins I'apèndix de l'obra de P. DE MARCA, De Concordia Sacerdotii et Imperii 1, Paris 1669 , pp. 250-251).

13 Promulgat a Clermont (1130), cànon XIII (MANSI XXI, col. 440), Reims (1131), cànon XVII (MANSI XXI, cols. 461-462), Laterà II (1139), cànons XVIII, XIX i XX (MANSI XXI, col, 531) i Reims (1148), canon XV (MANSI XXI, col. 717).

14 F. VALLS I TABERNER, «Ein Konzil zu Lerida im Jahre $1155 \%$, Sonderdruck aus Papsttum und Kaisertum, Forschungen zur politischen Geschichte und Geisteskultur des Mittelalters, München 1925, pp. 364-368.

15 Sobre els concilis laterans abans esmentats: C. HEFELE et H. LECLeRCQ. Histoire des Conciles V, la. part, Paris 1912, pp. 630 -644 (Latera I) i 721-746 (Laterà II). 
fos recollida també en l'assemblea de 1173, car la manca del document original o de còpies més properes fan pensar en la pèrdua documental d'algun d'aquests acords. La renovació de la Treva era un fet freqüent en la majoria de concilis i sínodes del segle XII, després de les mesures de generalització de la Pau i Treva preses en el concili de Clermont de 1095.

Totes aquestes disposicions de 1173 assenyalen l'intervencionisme del papat en els afers de Catalunya. El cardenal Jacint dictava la política d'Alexandre III (anteriorment ja estava al servei d'Adrià IV), impulsant el moviment reformista que volia enfortir la independència dels estaments eclesiàstics enfront de les ingerències del poder laic i de la violència feudal. Aquesta reforma, començada a programar durant el segle XI, tingué molt a veure amb la formació del moviment de la Pau i Treva. A Catalunya, després de l'impacte de l'obra d'Oliba, es recolliren els fruits dels importants concilis de Clermont de 1095 i 1130 . Fou Oleguer, bisbe de Barcelona i participant directe d'aquest corrent, el qui imposà les normes reformadores en l'assemblea de Barcelona de 1131, recollint cànons elaborats en el concili de Clermont de l'any anterior ${ }^{16}$. Importa destacar el sentit de croada contra els infidels que tenien tots aquests concilis. La Pau i Treva era la garantidora que dins els regnes cristians havia de regnar la pau si es volien portar a terme els objectius de conquesta. El cardenal Jacint impulsà més endavant la corada peninsular, que tenia uns trets ben específics: la seva llarga durada $\mathrm{i}$ la proximitat de l'enemic, elements que motivaren ja al segle XI l'intervencionisme papal. Paral-lelament, el poder laic, encara en plena formació, adoptà la institució de Pau i Treva per bastir el seu aparell d'estat i el seu domini territorial.

El mateix any 1173, Alfons I imposava l'autoritarisme del príncep, i prenia com a seva la Pau, entesa ara com una Pau territorial, en certa manera pública, en l'assemblea de Fondarella. Bisson comenta una Pau per al Rosselló del mateix any que respon a aquesta

16 Per als concilis de Clermont, Reims, Pisa i Tours, he consultat la mateixa obra citada a la nota 16. Les meves notes només pretenen una aproximació no exhaustiva dels precedents més destacats del concili de Lleida de 1173, per tal de ressaltar la universalitat dels acords conciliars del s. XII. 
política transformadora ${ }^{17}$. Guillem de Torroja ja era un gran col-laborador de Ramon Berenguer IV durant la seva etapa de bisbe de Barcelona (conquestes de Tortosa i Lleida) i del mateix Alfons I (assistí a l'assemblea de Fondarella). En el cas, però, del concili de Lleida del 1173, l'arquebisbe de Tarragona juga el paper reformista dictat per Roma i el seu legat (ell mateix serà nomenat legat pontifici). En aquest sentit, és evident la tensió entre els dos conceptes de Pau i Treva coixistents, que responen a dos grans poders que s'enfronten (recordem el problema de les investidures) i que col-laboren en determinades qüestions (especialment en el camp de les croades i, dins d'aquest context, la introducció dels ordes militars). La política de Ramon Berenguer IV a favor de la instal-lació dels templers a Catalunya és aprovada per Oleguer en l'assemblea de 113418.

L'evolució posterior de les assemblees de Pau i Treva sembla que confirma clarament el triomf de les tesis laiques de poder, i per tant, del seu concepte de Pau territorial. Així, els estatuts de Fondarella s'aplicarien al comtat d'Urgell el $1187^{19}, \mathrm{i}$ amb ampliacions importants es mantindrien durant les assemblees de Pere I i Jaume I. Les discussions canòniques reflecteixen aquest triomf quan, el segle XIII, Ramon de Penyafort considera la Pau com a eina bàsica per a l'autoritat pública. Les tensions entre el poder laic i la classe feudal, evidents en els regnats de Pere I i Jaume I, poden explicar les aliances i els interessos mutus entre l'Església i els comtes-reis. De fet, l'aliança començà a pactar-se a partir de la política d'autoafirmació de Ramon Berenguer I com a príncep de Barcelona, tal com reflecteix el text de l'assemblea de Barcelona de 106420 .

17 T. BISsoN, «Une paix peu connue pour le Roussillon (A.D. 1173)», Droit privé et institutions régionales. Études... Jean Yver, Roma 1976, pp. 69-76. El text de I'assemblea de Fondarella (1173) fou publicat a Cortes de los antiguos reinos de Aragón y de Valencia y Principado de Cataluña, publicadas por la Real Academia de la Historia. Cortes de Cataluña 1, 1a. part, Madrid 1896, pp. 55-62.

18 P. De Bofarulu, Colección de documentos inéditos del Archivo General de la Corona de Aragón IV, Barcelona 1849. doc. XI, pp. 29-33.

19 F. VALLS I TABERNER, "Pau i Treva del comtat d'Urgell en 1187 , Revista Juridica de Catalunya XXXIV, 1928, pp. 354-356.

20 F. FITA, «Cortes y Usajes de Barcelona en 1064. Textos inéditos", Boletín de la Real Academia de la Historia XV1-XVII, 1890, pp. 389-393. Els Usatges incorporarien nombroses Constitucions de Pau i Treva. 
Les Paus d'Olèrdola i de Cerdanya, abans esmentades, continuen aquesta línia, ara conduida pel comte Ramon Berenguer III ${ }^{21}$.

Els estatuts de Pau i Treva acordats al llarg del segle XIII són clarament manipulats pels monarques; la Pau s'associa a la institució reial. Per aquest motiu, les assemblees eclesiàstiques, com la de Lleida de 1173 , cal considerar-les fets marginals quant a contingut polític, destinades a reglamentar qüestions d'ordre intern de l'estament eclesiàstic, i amb poca incidència dins els estaments laics. Les assemblees del segle XI, en canvi, tingueren forta ressonància en les classes populars i les jerarquies feudals, i per aquest motiu el poder públic, encara molt feble, veié en la Pau i Treva una eina útil per a reforçar les seves estructures. Els estatuts lleidatans de 1173 són clarament defensius, mentre que els estatuts de Pau instituitts pels prínceps tenen una intencionalitat fortament expansiva. Naturalment, aquestes assemblees eclesiàstiques, concilis i sínodes, continuarien produint-se (malauradament, desconeixem documentalment moltes assemblees dels segles XI-XIII, car és lògic pensar que cada diòcesi aplicaria els principis de la Pau i Treva segons les seves necessitats; en aquest cas, la destrucció de documentació conciliar ha estat determinant per a la nostra ignorància), però bandejades per les grans assemblees reials que esdevindrien evolutivament veritables reunions legislatives i pactistes. Ens referim a la formació de les Corts²2.

21 J. Rius i Serra, Cartulario de San Cugat del Vallés III, Barcelona 1947. doc. 801, pp. 3-4 (Olèrdola): F. MiQUEL I Rosel. . Liber Feudorum Maior II, Barcelona 1945, doc. 691, p. 200 (Cerdanya).

22 També he consultat per a l'estudi del concili de Lleida de 1173 les obres següents: P.B. GAMS, Die Kirchengeschichte von Spanien IV, Regensburg 1864, pp. 205-207 (edició anastàtica de 1956, Graz): P. PALAZzINI, Dizionario dei Concili II, Roma 1964, p. 253; M. GUALLAR PÉREZ, Los Concilios Tarraconenses celebrados en Lérida (siglos VI-Xv), Lleida 1975, pp. 79-102; Th. BissoN, «"Quanto Personam Tuam" (X 2.24.18): Its original significance», Monumenta Iuris Canonici. Series C: Subsidia, v, Città del Vaticano 1976, pp. 229-249: Th. BIsson, aOrganized Peace in Southem France and Catalonia (ca. 1140-ca. 1233)», The American Historical Review 82, 1977, pp. 290-311; Th. BISSON, «El Feudalismo en la Cataluña del siglo XII», Estructuras feudales y feudalismo en el mundo mediterráneo (siglos X-XIIr. Col-loqui de Roma de 1978. Edició castellana de 1984, pp. 66-91. 